\title{
Genetic variants of Anaplasma phagocytophilum from 14 equine granulocytic anaplasmosis cases
}

\author{
Cornelia Silaghi ${ }^{1 *}$, Gabriele Liebisch ${ }^{2}$ and Kurt Pfister ${ }^{1}$
}

\begin{abstract}
Background: Equine Granulocytic Anaplasmosis (EGA) is caused by Anaplasma phagocytophilum, a tick-transmitted, obligate intracellular bacterium. In Europe, it is transmitted by Ixodes ricinus. A large number of genetic variants of A. phagocytophilum circulate in nature and have been found in ticks and different animals. Attempts have been made to assign certain genetic variants to certain host species or pathologies, but have not been successful so far. The purpose of this study was to investigate the causing agent A. phagocytophilum of 14 cases of EGA in naturally infected horses with molecular methods on the basis of 4 partial genes (16S rRNA, groEL, msp2, and msp4).

Results: All DNA extracts of EDTA-blood samples of the horses gave bands of the correct nucleotide size in all four genotyping PCRs. Sequence analysis revealed 4 different variants in the partial 165 rRNA, groEL gene and msp2 genes, and 3 in the msp4 gene. One 16S rRNA gene variant involved in 11 of the 14 cases was identical to the "prototype" variant causing disease in humans in the amplified part [GenBank: U02521]. Phylogenetic analysis revealed as expected for the groEL gene that sequences from horses clustered separately from roe deer. Sequences of the partial msp2 gene from this study formed a separate cluster from ruminant variants in Europe and from all US variants.

Conclusions: The results show that more than one variant of $A$. phagocytophilum seems to be involved in EGA in Germany. The comparative genetic analysis of the variants involved points towards different natural cycles in the epidemiology of A. phagocytophilum, possibly involving different reservoir hosts or host adaptation, rather than a strict species separation.
\end{abstract}

\section{Background}

Equine Granulocytic Anaplasmosis (EGA) is caused by Anaplasma phagocytophilum, a tick-transmitted, obligate intracellular bacterium. The vectors are ticks of the genus Ixodes; the main vector in Europe is I. ricinus, in North America I. pacificus and I. scapularis. As no transovarial transmission has been shown, a reservoir animal is necessary for the maintenance in nature [1]. Before 2001, when a reclassification based on $16 S$ rRNA gene similarities was proposed, the causing agent of EGA was known as Ehrlichia equi, which was part of the E. phagocytophila group (including also E. phagocytophila, the causing agent of tick-borne fever of ruminants, and the Human Granulocytic Anaplasmosis

\footnotetext{
* Correspondence: cornelia.silaghi@tropa.vetmed.uni-muenchen.de ${ }^{1}$ Comparative Tropical Medicine and Parasitology, Faculty of Veterinary Medicine, Ludwig-Maximilians-Universität, Leopoldstr. 5, 80802 Munich, Germany

Full list of author information is available at the end of the article
}

(HGA) - agent [2]). Different partial $16 S$ rRNA gene variants of A. phagocytophilum have been detected in previous studies from various host animals and ticks [3-7].

The first case of EGA was reported from northern California in 1969 [8]. Since then reports came from North America and different European countries [9-17]. EGA is an acute febrile disease with an average incubation period of 1-2 weeks. Clinical signs include high fever, depression, anorexia, ataxia, icterus and a lower limb oedema; laboratory findings include thrombocytopenia, anaemia and leucopenia. These abnormalities have been shown both in natural and experimental infections $[14,18,19]$. The administration of tetracyclines is known as an effective treatment [20], but experimental infection has demonstrated that horses can make a full recovery without treatment [21]. This may account for the relatively high seropositivity as reported in horses in Italy (17.03\%) and Denmark $(22.3 \%)$ [22,23]. No significant difference was found in the seroprevalence between horses with or
C Biomed Central 
without suspicion of vector-borne diseases, which suggests the occurrence of subclinical infections [22]. Persistence of A. phagocytophilum was demonstrated in the bloodstream of horses after experimental infection and was not related to clinical disease, raising the question about persistency of a natural infection after an acute outbreak [21]. The existence of persistent infection with a cyclic bacteraemia has also been demonstrated in lambs after experimental infection [24]. The epidemiology of $A$. phagocytophilum differs between the continents: the outcome of disease in humans is more severe in the US, whereas disease in cattle is virtually non-existent; by contrast, disease is severe in cattle and sheep in Europe, but much rarer and milder in humans [1]. The $A$. phagocytophilum variant pathogenic for cattle (formerly E. phagocytophila) caused a seroconversion in horses without clinical disease [25]. By contrast, experimental infection with the HGA-agent caused a clinical disease in horses, undistinguishable from EGA [26] and even the death of a horse in another experimental study [27]. Genetic variations have been found previously on basis of the $16 S$ rRNA, groEL, msp2, msp 4 and ankA gene in $A$. phagocytophilum from ticks and animals, however it was not possible to attribute genetic variants to a certain host or geographic origin [3,5-7,28-30]. These investigations showed that $A$. phagocytophilum seems to show certain genetic heterogeneity; because of this we hypothesised that genetic heterogeneity would also exist in A. phagocytophilum naturally infecting horses and causing EGA. Several steps were taken: from 14 naturally infected horses with clinical EGA, first the $16 S$ rRNA gene was partially amplified and sequenced to gain a general overview of the genetic variety involved. To further analyse the variants involved in equine infections, partial groEL, $m s p 2$, and $m s p 4$ genes were amplified and sequenced. More than one partial $16 S$ rRNA gene variant was involved in equine infection and genetic variations were also detected in the other amplified parts of genes.

\section{Results}

All 14 samples were confirmed positive for $A$. phagocytophilum by using real-time PCR. The clinical data available for these cases corresponded to the typical clinical signs in EGA [19]. All four genotyping PCRs gave bands of the correct nucleotide size for the partial genes (16S rRNA, groEL, msp2 and msp4). The sequences obtained from this study have been deposited in GenBank [GenBank: JF893886-JF893940, JF907577]. The nucleotide differences are shown in Table 1.

\section{S rRNA gene sequences}

Sequence analysis revealed 4 types in the partial $16 S$ rRNA gene (497 bp; here called "A" $(\mathrm{n}=1)$, " $\mathrm{B}$ " ( $\mathrm{n}=$ $11)$, "D" (n = 1), "S" $(\mathrm{n}=1))$. The $16 S$ rRNA gene variant "B" involved in 11 of the 14 cases was identical to the "prototype" variant causing disease in humans in the amplified part [GenBank: U02521]. The partial $16 S$ rRNA gene sequences from this study had $99 \%$ to $100 \%$ similarity to each other and to the A. phagocytophilum strain HZ [GenBank: NC_007797].

\section{GroEL gene sequences}

Four variants were also found in the partial groEL gene (530 bp; here called "a" $(\mathrm{n}=1)$, "b" $(\mathrm{n}=11)$, " $\mathrm{r}$ " $(\mathrm{n}=1)$, "l" $(\mathrm{n}=1))$. The partial groEL gene sequences from this study had $99 \%$ to $100 \%$ similarity on basis of nucleotides to each other and $98 \%$ to $99 \%$ to the A. phagocytophilum strain HZ [GenBank: NC_007797]. These nucleotide changes in the partial groEL gene did not result in amino acid changes.

\section{Msp2 gene sequences}

The partial msp2 gene revealed also 4 variants (893 bp; here called "I" ( $n=4)$, "II" ( $n=7)$, "III" $(n=2)$, "IV" ( $n=$ $1)$ ). The two main $m s p 2$ gene variants "I" and "II" only differed in a single nucleotide polymorphism in the amplified part (nucleotide position 136), which resulted in one amino acid exchange. $M s p 2$ variant "III" had five nucleotide differences from "II" (resulting in one amino acid difference) and 6 nucleotide differences from "I" (resulting in two amino acid differences). Type "IV" had 5 nucleotide differences from "III", 10 nucleotide differences from "II" and 11 nucleotide differences from "I", resulting in 3, 4 and 5 amino acid differences, respectively (Table 1). On basis of nucleotides, all partial msp2 gene sequences from this study had $98 \%$ to $100 \%$ similarity amongst each other and $92 \%$ to $93 \%$ similarity to the A. phagocytophilum strain HZ [NC_007797]. On basis of amino acids, the similarity was $98 \%$ to $100 \%$ for sequences from this study amongst each other and $87 \%$ to $88 \%$ to the A. phagocytophilum strain HZ [GenBank: NC_007797].

\section{Msp4 gene sequences}

Three variants were detected in the partial $m s p 4$ gene (343 bp; here called " $c$ " $(\mathrm{n}=11)$, " $s$ " $(\mathrm{n}=1)$ and " $d$ " (n $=1)$ ). For one sequence only 306 bp could be evaluated. The partial 343 bp msp 4 gene sequences from this study had $96 \%$ to $100 \%$ similarity on basis of nucleotides amongst each other and $96 \%$ to $97 \%$ to the $A$. phagocytophilum strain HZ [GenBank: NC_007797]. The nucleotide difference at position 427 in variant " $d$ " resulted in one amino acid exchange (Table 1).

For the $11 \mathrm{~A}$. phagocytophilum samples from horses with the $16 S$ rRNA gene variant "B", the msp4 ("variant $c$ ") and groEL (variant "b") gene variant were identical, whereas on the basis of the msp2 it was possible to distinguish two different types. The remaining three samples were different from each other in the partial analysed genes and from the other 11 samples (Table 2). 
Table 1 Nucleotide differences of Anaplasma phagocytophilum in the amplified partial genes.

\begin{tabular}{|c|c|c|c|c|c|c|c|c|c|c|c|c|c|c|}
\hline Gene & variant $^{\mathrm{e}}$ & Nucleotide position $^{\text {h }}$ & & & & & & & & & & & & \\
\hline & & 76 & 77 & 84 & 125 & 222 & 376 & & & & & & & \\
\hline \multirow[t]{7}{*}{$16 S r R N A^{a}$} & A & $\bar{A}$ & $A$ & $G$ & $G$ & $A$ & $A$ & & & & & & & \\
\hline & B & A & A & G & G & A & G & & & & & & & \\
\hline & D & G & $A$ & $A$ & A & G & G & & & & & & & \\
\hline & $S$ & A & G & G & G & A & G & & & & & & & \\
\hline & $x^{f}$ & G & A & A & G & A & G & & & & & & & \\
\hline & $Y^{g}$ & G & A & G & G & A & G & & & & & & & \\
\hline & & 660 & 840 & 933 & 1013 & & & & & & & & & \\
\hline \multirow[t]{5}{*}{$\operatorname{groEL}^{\mathrm{b}}$} & a & C & $C$ & $C$ & A & & & & & & & & & \\
\hline & b & $\mathrm{T}$ & C & C & A & & & & & & & & & \\
\hline & $r$ & C & $\mathrm{T}$ & C & A & & & & & & & & & \\
\hline & 1 & C & $\mathrm{T}$ & $\mathrm{T}$ & G & & & & & & & & & \\
\hline & & 158 & 136 & 277 & 288 & 376 & 393 & 917 & 927 & 939 & 943 & 966 & & \\
\hline \multirow[t]{5}{*}{$M_{s p 2^{C}}$} & I & $\bar{G}$ & $A$ & $A$ & G & $A$ & $T$ & A & A & G & $T$ & G & & \\
\hline & II & G & G & A & G & A & T & A & A & G & $\mathrm{T}$ & G & & \\
\hline & III & G & G & A & G & A & $T$ & G & G & $\mathrm{T}$ & G & A & & \\
\hline & IV & A & G & G & A & G & G & G & G & $T$ & G & A & & \\
\hline & & 375 & 390 & 405 & 411 & 423 & 427 & 507 & 510 & 516 & 588 & 618 & 672 & 678 \\
\hline \multirow[t]{3}{*}{$M s p 4^{d}$} & c & $\bar{T}$ & $A$ & $C$ & $A$ & G & G & $C$ & $T$ & $C$ & $\mathrm{~T}$ & $A$ & $A$ & $C$ \\
\hline & $d$ & $C$ & G & $\mathrm{T}$ & G & G & A & C & $T$ & $C$ & $\mathrm{~T}$ & $C$ & A & C \\
\hline & $s$ & $C$ & G & $\mathrm{T}$ & G & A & G & $\mathrm{T}$ & C & $\mathrm{T}$ & $C$ & $c$ & $\mathrm{G}$ & $\mathrm{T}$ \\
\hline
\end{tabular}

Anaplasma phagocytophilum $\mathrm{HZ}$ complete genome [NC_007797] was used as reference strain: Nucleotide positions indicate the relative position to the genes:

a 1,433 bp of rrsA 165 ribosomal RNA [Gene ID: 3930754],

b 1,653 bp of groEL chaperonin GroEL [Gene ID: 3930333],

c 1,098 bp of APH_1361 major surface protein 2 [Gene ID: 3930122] and

d 849 bp of msp4 major surface protein 4 [Gene ID: 3930710]

e Not official nomenclature: It has been used in the same manner in another publication (7), the letters here correspond to the ones from that publication. $16 \mathrm{~S}$ rRNA gene types are shown in upper case letters; groEL gene types in lower case letters; msp4 gene types in lower case letters in italics; msp2 gene types in Roman numbers.

${ }^{f}$ GenBank: [FJ812403]

g GenBank: [FJ812406]

${ }^{\mathrm{h}}$ non-synonymous substitutions are highlighted in bold.

\section{Phylogenetic analysis}

Phylogenetic analysis of the partial groEL (530 bp), the partial msp2 (893 bp) and the partial msp4 (343 bp) genes was performed with sequences from this study and selected sequences from GenBank (Figure 1). As previously shown, the groEL tree clustered into $A$. phagocytophilum sequences from roe deer and those from other species. The horse sequences clustered within the "other species" group (Figure 1A). Interestingly, one of the partial groEL sequences from horses in this study (variant "a"; GenBank [JF893919]) has been detected previously in roe deer when comparing the amplified $530 \mathrm{bp}$, according to the GenBank entry [AF478558]. The msp2 phylogenetic tree showed clusters in sequences from US and from Europe; and within these clusters, ruminants clustered separately (Figure 1B). The msp4 phylogenetic tree showed that also US strains clustered separately from the European sequences. The variant "c" clustered separately from the others with a partial msp4 gene previously deposited in GenBank whereas the other two variants " $s$ " and " $d$ " clustered with sequences from ruminant species (Figure 1C).

\section{Discussion}

For 14 cases of EGA the causing agent A. phagocytophilum was analysed with molecular methods for variations in four partial genes. Altogether, four different partial $16 S$ rRNA gene variants of $A$. phagocytophilum were detected to infect horses in Germany. The variant "B" was found identical to the "prototype" variant causing disease in humans in the amplified region [GenBank: U02521] and it was discovered in 11 horses.

This variant has previously been detected in dogs, horses and in roe deer, red deer and sheep $[31,32,17,15,7,5]$. The $16 S$ rRNA gene variant "B" seems rather rare in ticks in Germany whereas the most frequent variant in ticks seems to be "A" [3, 29, 33, Schorn S. unpublished data]. It was detected in a sample from 
Table 2 Details of the horses included in this study and the respective partial genes of Anaplasma phagocytophilum that were detected in them.

\begin{tabular}{|c|c|c|c|c|c|c|c|}
\hline \multirow[b]{2}{*}{ Breed } & \multirow[b]{2}{*}{$\mathrm{Age}^{\mathrm{a}}$} & \multirow[b]{2}{*}{$\operatorname{Sex}^{\mathbf{b}}$} & \multirow[b]{2}{*}{ Month and year of diagnosis } & \multicolumn{4}{|c|}{ Gene variants $^{c}$} \\
\hline & & & & $16 S$ rRNA & groEL & Msp2 & Msp4 \\
\hline Pony & 20 & Mc & Jul 2007 & B & $b$ & 1 & c \\
\hline Hanoverenian & n. k. & $\mathrm{F}$ & Oct 2007 & B & $b$ & I & c \\
\hline Warmblood & 6 & Mc & Apr 2004 & B & $b$ & I & c \\
\hline Standardbred & 8 & Mc & Jul 2004 & B & $b$ & । & $c$ \\
\hline Hanoverenian & 13 & $\mathrm{~F}$ & May 2006 & B & $\mathrm{b}$ & $\|$ & c \\
\hline Westphalian Warmblood & 11 & Mc & Oct 2007 & B & $b$ & $\|$ & c \\
\hline Pony & 19 & Mc & May 2008 & B & $b$ & $\|$ & c \\
\hline English Thoroughbred & 15 & $\mathrm{~F}$ & Jun 2008 & B & $b$ & $\|$ & c \\
\hline Icelandic horse & 9 & Mc & Jun 2009 & B & $b$ & $\|$ & c \\
\hline Friesian & 12 & M & Jun 2009 & B & $b$ & $\|$ & c \\
\hline Quarter horse & n. k. & Mc & Jun 2009 & B & $\mathrm{b}$ & $\|$ & c \\
\hline Warmblood & 9 & Mc & Aug 2008 & $\bar{A}$ & $\mathrm{a}$ & III & $c$ \\
\hline English Thoroughbred & 11 & $M c$ & May 2005 & $\bar{D}$ & $r$ & IV & $d$ \\
\hline Warmblood & 13 & Mc & Jun 2007 & $\bar{S}$ & I & III & s \\
\hline
\end{tabular}

${ }^{a}$ age in years at the time of diagnosis; $n$. k., not known

${ }^{\mathrm{b}} \mathrm{F}$, female; M, male; Mc, male castrated

' See Table 1

one horse in this study. $16 S$ rRNA gene type "S" has been detected in sheep, red deer, roe deer, ibex and $I$. ricinus $[7,3,5]$, whereas type " $\mathrm{D}$ " has not been detected yet. Previous studies could not show a host species segregation on basis of the $16 S$ rRNA gene [5,7]. However, by comparing data from our study to GenBank and to previous own investigations [6,7], it became evident that there seem to be $16 S$ rRNA gene variants infecting wild and domestic ruminants (e.g. "X","Y" (Table 1), as described in $[6,7])$, and others being the main variants causing disease in humans, horses and dogs (e.g. "B"; $[30,32,34])$. This could thus indicate potential different natural cycles, even when variants can not be attributed to a particular species. Two variants detected from the clinical EGA cases in this study ("B", "S") seem, however, not confined to domestic animals, but also appear in wild animals which might act as reservoirs (like red deer and roe deer), whereas the possibly "apathogenic" variants ("X", "Y", Table 1), seem to be specific for wild ruminant populations and possibly goats [6,7]. Several questions remain unanswered: may a reservoir animal or a tick form a "bridge" between a potential wild animal and domestic cycle, or could the infection of domestic animals be considered a "spill-over" of variants like "B" and "S"? I. e. are all variants circulating in tick-ruminant cycles, and only a small variety of those cause disease? Horses, dogs and humans have previously been proposed as accidental hosts [35].

The American variant Ap-V1 (matching "X" [6,7] in the amplified part of the $16 S$ rRNA gene), which is supposedly apathogenic, probably has the white-tailed deer as natural reservoir [36]. This variant seems not to cross to dogs, horses and humans either. Two fully different enzootic cycles in nature were suggested for the Western United States as there was no evidence for spatial, genetic or clinical overlap between A. phagocytophilum variants from granulocytic anaplasmosis cases (humans, horses and dogs) and those from the natural wildlife reservoir, the dusky-footed wood rat enzootic cycle [37].

The partial groEL gene variant "b" from this study has previously been detected in horses with EGA in Europe $[15,19,38]$, but horses suffering from EGA from Italy (Sardinia) contained different variants, which were not detected in this study [28]. GroEL-variant "r" has previously been detected from red deer in Slovenia and "l" has been previously detected from an I. ricinus tick in Germany. GroEL-variant "a" has been detected from both dog and roe deer in Slovenia. The clustering of the groEL gene in phylogenetic analysis into a cluster containing sequences from roe deer and another containing sequences derived from other species may show different ancestry for different $A$. phagocytophilum variants. Some variants may have evolved in a natural cycle adapted to roe deer which may be separate from other variants involving other host species. However, the variant "a" has also been detected from roe deer, which seems to be exceptional when comparing the clustering of this and of previous studies [28]. This observation deserves more attention in future studies on genetic variants of $A$. phagocytophilum. Whereas the observed nucleotide substitutions in the partial groEL gene did not result in amino acid changes, the variation in the 


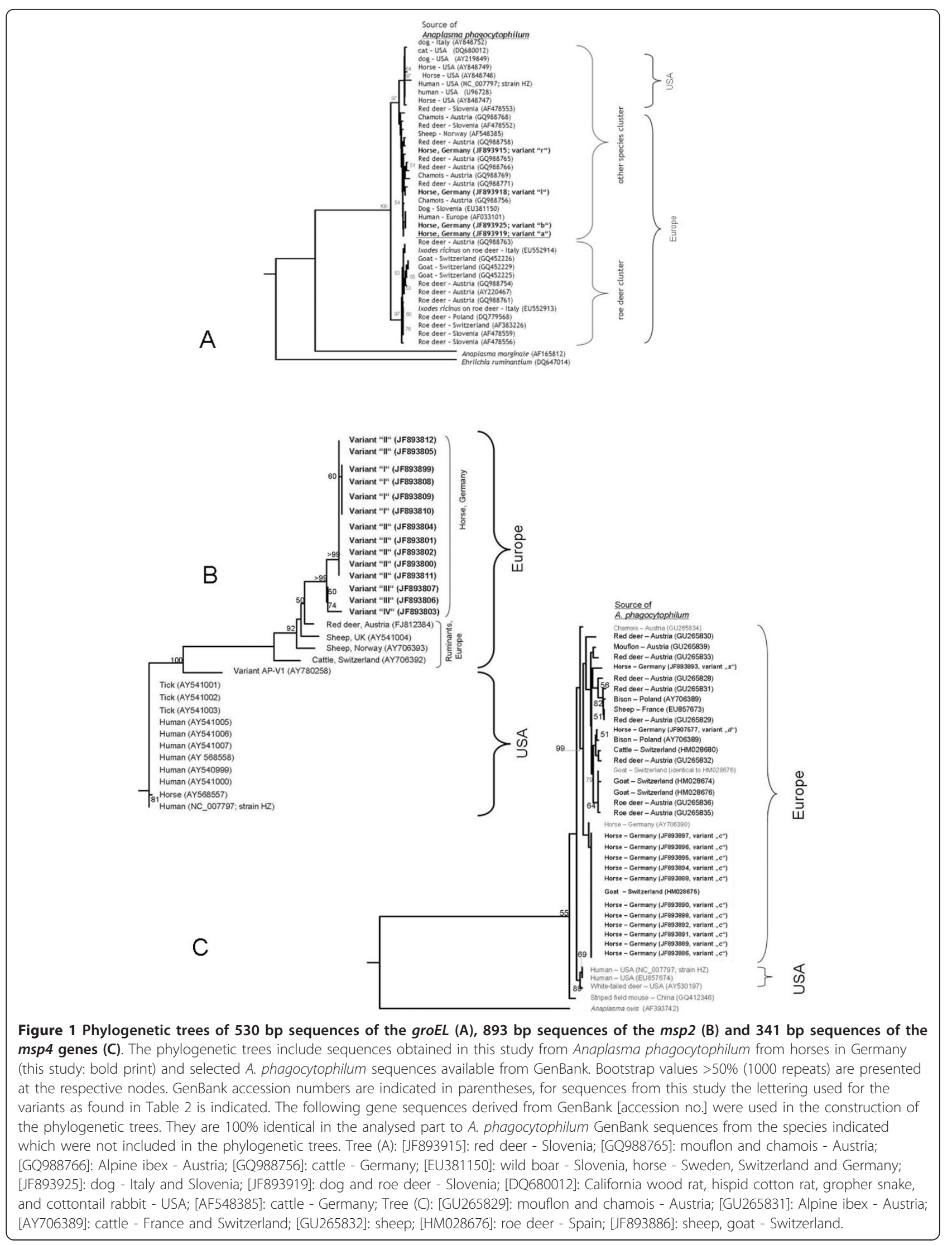


partial major surface protein 2 coding gene did. In the phylogenetic analysis, the partial $m s p 2$ gene showed strong clustering between the continents. This may be due to a possible reaction or adaptation to the different vector or host species in the different geographic locations, as it may reflect different host immunity and an adaptation of the pathogen to it [39]. On the other hand, it may be that host specificity or susceptibility are more important than geographic origin. In an experimental study on cross transmission in the US, host susceptibility and transmissibility of A. phagocytophilum may have played a more important role than the vector tick itself [40], which suggests different reservoir host cycles.

The amplification of the partial msp 4 gene showed little heterogeneity among horses, both on the nucleotide and at the amino acid level, whereas in large wild animals it showed great heterogeneity, also on amino acid level [7]. In a previous study, the partial msp4 gene variants from ruminants and those from dogs, horses and humans clustered separately [30]. It was suggested that A. phagocytophilum from ruminants may share characteristics, like reservoir and pathogenicity, and that they may be different from the variants found in humans. This strengthens the hypothesis that different enzootic cycles or niches of different variants possibly involving different reservoir hosts exist in nature. A thorough study of the ankA gene from different animal sources came to similar conclusions [5,34]. It was hypothesised that ruminant species can host a larger variety of $A$. phagocytophilum isolates due to a possible co-evolution of host and pathogen [34]. However, we detected two variants in the partial msp4 gene that clustered within the ruminant cluster. This raises the question whether these two cases in the horses may represent a "spillover" from ruminant variants, or whether the clustering of the msp4 gene phylogenetic tree may only be weakly supported due to the relatively short sequence used for the comparative analysis. The use of $16 S$ rRNA gene or parts of it as a tool for the molecular characterisation of A. phagocytophilum has been criticized $[4,5,32]$. Nonetheless the $16 S$ rRNA gene may be very useful, on a broader level, for discriminating variants eliciting granulocytic anaplasmosis from those from a potential wild ruminant cycle. Even though the true genetic variety may be much larger as has been shown e.g. for $a n k A$ and $m s p 2$ ([3]; results from this study) and a more comprehensive analysis of genetic variants is necessary, the $16 S$ rRNA gene typing seems a good method for initial typing.

\section{Conclusions}

We conclude that more than one genetic variant of $A$. phagocytophilum infects horses and causes EGA in
Germany and possibly elsewhere. One main causing variant was $100 \%$ similar in the amplified part of the partial 16S rRNA gene to the one pathogenic for humans [GenBank: U02521], but other variants caused clinically apparent infection, too. Comparing this data to sequence data from ticks another type ("A") seems to be the most prevalent one in ticks, but seems to be rather rare in causing disease in horses [[29], Schorn et al., unpublished data]. This gives a strong basis for hypothesising that $A$. phagocytophilum may exist in different natural cycles involving different reservoir hosts. This tendency has also been shown in previous studies $[5,30]$. We further conclude that for a preliminary comparative typing of $A$. phagocytophilum the partial $16 S$ rRNA gene seems a useful tool. Therefore, even when other genes are studied for phylogenetic or other differentiation or in the search for better markers for typing, $16 \mathrm{~S} r R N A$ variant typing should also be performed.

\section{Methods}

\section{Horses and clinical assessment}

Fourteen cases of clinical EGA, diagnosed from 2004 to 2009, were included in this study (Table 2). The horses were from three federal states of Germany: Lower Saxony $(\mathrm{n}=6)$, North-Rhine Westphalia $(\mathrm{n}=6)$ and Bavaria $(n=2)$ (Figure 2). The diagnosis which had been requested by the veterinarians for routine diagnostics at the time of infection had been taken with Giemsa stained buffy coat smears. In all 14 horses, morulae had been detected in the granulocytes. For 3 horses, diagnosis at the time had also been taken by PCR. EDTAblood which was left over from the routine diagnosis of the horses was preserved at $-20^{\circ} \mathrm{C}$ for further use in this study. All 14 animals were suffering from high fever, 8 of them recurring, 5 horses had icterus, 2 a lower limb oedema, and further 2 anorexia. 13 animals showed thrombocytopenia, 6 monocytopenia, and 5 lymphopenia, the total bilirubin was increased for 5 horses. 7 horses were previously treated with penicillin or other antibiotics not acting against $A$. phagocytophilum.

\section{DNA-Extraction and Polymerase Chain Reaction}

DNA was extracted with the HighPure PCR Template Preparation Kit (Roche, Mannheim, Germany). The presence of specific A. phagocytophilum DNA was verified in all samples with a real-time PCR targeting the $m s p 2$ gene as previously described $([41,6])$. The conditions and primers for sequence analysis of the partial $16 \mathrm{~S}$ $r R N A$, groEL, $m s p 2$, and $m s p 4$ genes are listed in Table 3. The PCRs were carried out on the thermocyclers GeneAmp System 2700/Veriti (Applied Biosystems, Weiterstadt, Germany) or an Eppendorf Mastercycler gradient (Eppendorf, Hamburg, Germany). The HotStarTaq Kit (Qiagen, Hilden, Germany) was used for all 


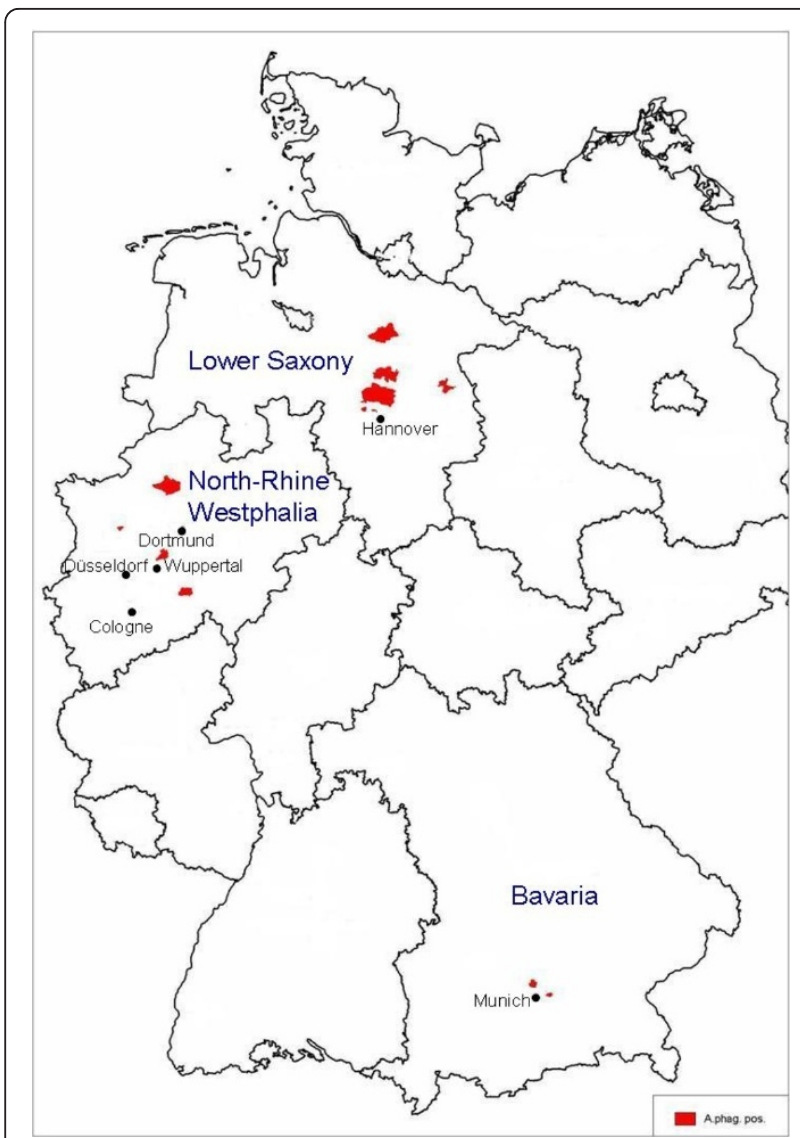

Figure 2 Map of Germany showing the origin of the horses included in this study. The location where the horses were staying at the time of diagnosis is shown according to the postal code in the respective districts (shaded in red) within the federal states. The map was created with Regiograph (GFK MACON AG, Waghäusel, Germany).
PCR experiments. Positive (DNA of $A$. phagocytophilum infected I. ricinus ticks) and negative (molecular biology grade water) controls were included in each PCR run. Successful amplification of the gene targets was verified with $2.0 \%$ agarose gel-electrophoresis after staining with GelRed $^{\mathbb{B}}$ (Biotium, Hayward, USA) and visualized under UV-light.

\section{Sequence Analysis}

PCR products were purified with the QIAquick PCR Purification Kit according to manufacturer's instruction (Qiagen, Hilden, Germany) and sent for sequencing with forward and reverse primers (Table 3) to Eurofins MWG Operon (Martinsried, Germany). The obtained chromatograms were evaluated with $\mathrm{Chromas}{ }^{\odot}$ Lite http://www.technelysium.com.au/chromas_lite.html. ClustalW2 was used to perform multiple sequence alignment of the sequences [45]. Nucleotide sequences were translated to amino acid level using Transeq http:// www.ebi.ac.uk/emboss/transeq/. Sequence homology searches were made by BLASTn analysis of GenBank http://www.ncbi.nlm.nih.gov.library.vu.edu.au/BLAST/.

\section{Phylogenetic analysis}

Phylogenetic analysis was carried out with the PHYLIP 3.67 software package [46] using the neighbor joining method. For this analysis 33 sequences of the partial groEL gene, 16 of the partial $m s p 2$ gene and 22 of the partial msp4 gene were used from GenBank. Distance matrices were calculated with the Kimura 2-parameter method using DNADIST. A bootstrap analysis was performed to test the stability of the trees with 1000

Table 3 Primers used for the PCRs for sequence analysis for Anaplasma phagocytophilum from horses in this study.

\begin{tabular}{|c|c|c|c|}
\hline Target Gene & Primers 5'-3' & Cycle conditions ** & Reference \\
\hline $16 S$ rRNA & $\begin{array}{l}\text { First reaction: } \\
\text { ge3a: CACATGCAAGTCGAACGGATTATTC } \\
\text { ge10r: TTCCGTTAAGAAGGATCTAATCTCC } \\
\text { Nested reaction*: } \\
\text { ge9f: AACGGATTATTCTTAATAGCTTGCT } \\
\text { ge2: GGCAGTATTAAAAGCAGCTCCAGG }\end{array}$ & $\begin{array}{l}40 \text { cycles (nested reaction: } 25 \text { cycles): } \\
30 \sec 94^{\circ} \mathrm{C}, 30 \sec 55^{\circ} \mathrm{C}, 1 \mathrm{~min} 72^{\circ} \mathrm{C}\end{array}$ & [42] \\
\hline groEL & $\begin{array}{l}\text { First reaction: } \\
\text { EphplgroEL-F: ATGGTATGCAGTITGATCGC } \\
\text { EphplgroEL-R: TCTACTCTGTCTITGCGTTC } \\
\text { Nested reaction*: } \\
\text { EphplgroEL-F: ATGGTATGCAGTITGATCGC } \\
\text { EphgroEL-R: TTGAGTACAGCAACACCACCGGAA }\end{array}$ & $\begin{array}{l}40 \text { cycles: } \\
30 \text { sec } 94^{\circ} \mathrm{C}, 30 \text { sec } 55^{\circ} \mathrm{C}, 45 \sec 72^{\circ} \mathrm{C}\end{array}$ & [28] \\
\hline Msp2 & $\begin{array}{l}\text { msp25: TTATGATTAGGCCTTTGGGCATG** } \\
\text { msp23:TCAGAAAGATACACGTGCGCCC** }\end{array}$ & $\begin{array}{l}35 \text { cycles: } \\
1 \text { min } 95^{\circ} \mathrm{C}, 1 \min 62^{\circ} \mathrm{C}, 1.5 \min 72^{\circ} \mathrm{C}\end{array}$ & [43] \\
\hline \multirow[t]{2}{*}{ Msp4 } & $\begin{array}{l}\text { First reaction: } \\
\text { MSP4AP5: ATGAATTACAGAGAATTGCTTGTAGG } \\
\text { MSP4AP3: TTAATTGAAAGCAAATCTTGCTCCTATG }\end{array}$ & $\begin{array}{l}40 \text { cycles: } \\
30 \text { sec } 94^{\circ} \mathrm{C}, 45 \sec 54^{\circ} \mathrm{C}, 1 \mathrm{~min} 72^{\circ} \mathrm{C}\end{array}$ & [30] \\
\hline & $\begin{array}{l}\text { Nested reaction*: } \\
\text { msp4f: CTATTGGYGGNGCYAGAGT } \\
\text { msp4r: GTTCATCGAAAATCCGTGGTA }\end{array}$ & & [44] \\
\hline
\end{tabular}

* Primers used for the sequencing reactions

** all PCR reactions: $15 \mathrm{~min} 95^{\circ} \mathrm{C}$ initial activation; $7 \mathrm{~min} 72^{\circ} \mathrm{C}$ final extension 
resamplings using SEQBOOT. Consensus trees were derived with CONSENSE.

\section{Acknowledgements}

The authors thank Sina Thienel and Claudia Thiel for technical assistance in the laboratory.

\section{Author details}

${ }^{1}$ Comparative Tropical Medicine and Parasitology, Faculty of Veterinary Medicine, Ludwig-Maximilians-Universität, Leopoldstr. 5, 80802 Munich, Germany. ${ }^{2}$ Zecklab, Up'n Kampe 3, 30938 Burgwedel, Germany.

\section{Authors' contributions}

CS organised and established the laboratory work, carried out the sequence and phylogenetic analysis and wrote the manuscript. GL provided the samples and clinical data for this study, and GL and KP critically revised the manuscript. All authors read and approved the final manuscript.

\section{Competing interests}

The authors declare that they have no competing interests.

Received: 28 April 2011 Accepted: 16 August 2011

Published: 16 August 2011

\section{References}

1. Woldehiwet Z: Anaplasma phagocytophilum in ruminants in Europe. Ann N Y Acad Sci 2006, 1078:446-460.

2. Dumler JS, Barbet AF, Bekker CP, Dasch GA, Palmer GH, Ray SC, Rikihisa Y, Rurangirwa FR: Reorganization of the genera in the families Rickettsiaceae and Anaplasmataceae in the order Rickettsiales: unification of some species of Ehrlichia with Anaplasma, Cowdria with Ehrlichia, and Ehrlichia with Neorickettsia, descriptions and designation of Ehrlichia equi and 'HGE agent' as subjective synonyms of Ehrlichia phagocytophila. Int J Syst Evol Microbiol 2001, 51:2145-2165.

3. Von Loewenich FD, Baumgarten BU, Schröppel K, Geißdörfer W, Röllinghoff M, Bogdan C: High Diversity of ankA sequences of Anaplasma phagocytophilum among Ixodes ricinus ticks in Germany. J Clin Microbiol 2003, 41:2033-5040.

4. Zeman P, Pecha M: Segregation of genetic variants of Anaplasma phagocytophilum circulating among wild ruminants within a Bohemian forest (Czech Republic). Int J Med Microbiol 2008, 298(Suppl 1):203-210.

5. Scharf W, Schauer S, Freyburger F, Petrovec M, Schaarschmidt-Kiener D, Liebisch G, Runge M, Ganter M, Kehl A, Dumler JS, Garcia-Perez AL, Jensen J, Fingerle V, Meli ML, Ensser A, Stuen S, von Loewenich FD: Distinct host species correlate with Anaplasma phagocytophilum ankA gene clusters. J Clin Microbiol 2011, 49:790-796.

6. Silaghi C, Scheuerle MC, Friche Passos LM, Thiel C, Pfister K: PCR detection of Anaplasma phagocytophilum in goat flocks in an area endemic for tick-borne fever in Switzerland. Parasite 2011, 18:57-62.

7. Silaghi C, Hamel D, Thiel C, Pfister K, Friche Passos LM, Rehbein S: Genetic variants of Anaplasma phagocytophilum in wild caprine and cervid ungulates from the Alps in Tyrol, Austria. Vector Borne Zoonotic Dis 2011.

8. Gribble DH: Equine ehrlichiosis. J Am Vet Med Assoc 1969, 155:462-469.

9. Büscher G, Gandras R, Apel G, Friedhoff $K T$ : [The 1st case of ehrlichiosis in a horse in Germany (Brief report)]. Dtsch Tierarztl Wochenschr 1984, 91:408-409.

10. Hermann M, Baumann D, Lutz H, Wild P: Erster diagnostizierter Fall von Equiner Ehrlichiose in der Schweiz. Pferdeheilkunde 1985, 1:247-250.

11. Bjoersdorff A: Ehrlichia equi infection diagnosed in horses. Svensk Veterinär Tidning 1990, 42:357-360.

12. Korbutiak E, Schneiders D: Equine Granulocytic Ehrlichiosis in the UK. Vet Rec 1994, 135:387-388.

13. Berrington A, Moats $R$, Lester $S$ : A case of Ehrlichia equi in an adult horse in British Columbia. Can Vet 1996, 37:174-175.

14. Bermann F, Davoust B, Fournier PE, Brisou-Lapointe AV, Brouqui P: Ehrlichia equi (Anaplasma phagocytophila) infection in an adult horse in France. Vet Rec 2002, 150:787-788.

15. Von Loewenich FD, Stumpf G, Baumgarten BU, Röllinghoff M, Dumler JS, Bogdan C: A case of equine granulocytic ehrlichiosis provides molecular evidence for the presence of pathogenic Anaplasma phagocytophilum (HGE agent) in Germany. Eur J Clin Microbiol Infect Dis 2003, 22:303-305.

16. Butler CM, Nijhof AM, Jongejan F, Van der Kolk JH: Anaplasma phagocytophilum infection in horses in the Netherlands. Vet Rec 2008, 162:216-218.

17. Jahn P, Zeman P, Bezdekova B, Praskova I: Equine granulocytic anaplasmosis in the Czech Republic. Vet Rec 2010, 166:646-649.

18. Reubel GH, Kimsey RB, Barlough JE, Madigan JE: Experimental transmission of Ehrlichia equi to horses through naturally infected ticks (Ixodes pacificus) from Northern California. J Clin Microbiol 1998, 38:2131-2134.

19. Franzén P, Aspan A, Egenvall A, Gunnarsson A, Åberg L, Pringle J: Acute Clinical, Hematologic, Serologic, and Polymerase Chain Reaction findings in horses experimentally infected with a European strain of Anaplasma phagocytophilum. J Vet Intern Med 2005, 19:232-239.

20. Madigan JE: Equine Ehrlichiosis. Vet Clin North Am Equine Pract 1993, 9:423-428

21. Franzén P, Aspan A, Egenvall A, Gunnarsson A, Karlstam E, Pringle J: Molecular evidence for persistence of Anaplasma phagocytophilum in the absence of clinical abnormalities in horses after recovery from acute experimental infection. J Vet Intern Med 2009, 23:636-642.

22. Passamonti F, Veronesi F, Cappelli K, Capomaccio S, Coppola G, Marenzoni ML, Piergili FD, Verini Supplizi A, Coletti M: Anaplasma phagocytophilum in horses and ticks: A preliminary survey of Central Italy. Comp Immunol Microbiol Infect Dis 2010, 33:73-83.

23. Hansen MGB, Christoffersen M, Thuesen LR, Petersen MR, Bojesen AM: Seroprevalence of Borrelia burgdorferi sensu lato and Anaplasma phagocytophilum in Danish horses. Act Vet Scand 2010, 52:3.

24. Granquist EG, Bårdsen K, Bergström K, Stuen S: Variant - and individual dependent nature of persistent Anaplasma phagocytophilum infection. Acta Vet Scand 2010, 52:25.

25. Pusterla N, Lutz H, Braun U: Experimental infection of four horses with Ehrlichia phagocytophila. Vet Rec 1998, 143:303-305.

26. Barlough JE, Madigan JE, DeRock E, Dumler JS, Bakken JS: Protection against Ehrlichia equi is conferred by prior infection with the Human Granulocytotropic Ehrlichia (HGE Agent). J Clin Microbiol 1995, 33:3333-3334.

27. Franzén P, Berg A-L, Aspan A, Gunnarson A, Pringle J: Death of a horse infected experimentally with Anaplasma phagocytophilum. Vet Rec 2007 160:122-125.

28. Alberti A, Zobba R, Chessa B, Addis MF, Sparagano O, Parpaglia MLP, Cupeddu T, Pintori G, Pittau M: Equine and Canine Anaplasma phagocytophilum strains isolated on the island of Sardinia (Italy) are phylogenetically related to pathogenic strains from the United States. Appl Env Microbiol 2005, 71:6418-6422.

29. Silaghi C, Gilles J, Höhle M, Fingerle V, Just FT, Pfister K: Anaplasma phagocytophilum infection in Ixodes ricinus, Bavaria, Germany. Emerg Infect Dis 2008, 14:972-974.

30. De la Fuente J, Massung RF, Wong SJ, Chu FK, Lutz H, Meli M, von Loewenich FD, Grzeszczuk A, Torina A, Caracappa S, Mangold AJ, Naranjo V, Stuen S, Kocan KM: Sequence analysis of the msp4 gene of Anaplasma phagocytophilum strains. J Clin Microbiol 2005, 43:1309-1317.

31. Johansson K-E, Pettersson B, Uhlén $M$, Gunnarsson A, Malmquist $M$, Olsson E: Identification of the causative agent of granulocytic ehrlichiosis in Swedish dogs and horses by direct solid phase sequencing of PCR products from the 16S rRNA gene. Res Vet Sci 1995, 58:109-112.

32. Zeman P, Jahn P: An entropy-optimized multilocus approach for characterizing the strains of Anaplasma phagocytophilum infecting horses in the Czech Republic. J Med Microbiol 2009, 58:423-429.

33. Leonard S: Untersuchung zur Häufigkeit von Borrelia burgdorferi sensu lato, Anaplasma phagocytophilum und Babesia spp. in Ixodes ricinus aus Bayern und Baden-Württemberg. Doctoral Thesis Ludwig-MaxmiliansUniverstät München, Institute of Comparative Tropical Medicine and Parasitology; 2005

34. Schauer S: Genetische Charakterisierung von Anaplasma phagocytophilum Stämmen. Doctoral Thesis Albert-Ludwigs-Universität Freiburg im Breisgau, Institute for Medical Microbiology and Hygiene; 2008.

35. Parola P, Davoust B, Raoult D: Tick- and flea-borne rickettsial emerging zoonoses. Vet Res 2005, 36:469-92.

36. Massung RF, Courtney JW, Hiratzka SL, Pitzer VE, Smith G, Dryden RL: Anaplasma phagocytophilum in white-tailed deer. Emerg Infect Dis 2005, 11:1604-6. 
37. Foley J, Nieto NC, Madigan J, Sykes J: Possible differential host tropism in Anaplasma phagocytophilum strains in the Western United States. Ann N Y Acad Sci 2008, 1149:94-97.

38. Pusterla N, Huder JB, Feige K, Lutz H: Identification of a Granulocytic Ehrlichia Strain isolated from a horse in Switzerland and comparison with other rickettsiae of the Ehrlichia phagocytophila genogroup. J Clin Microbiol 1998, 36:2035-2037.

39. Granquist EG, Stuen S, Lundgren AM, Braten M, Barbet AF: Outer Membrane Protein sequence variation in lambs experimentally infected with Anaplasma phagocytophilum. Infect Immun 2008, 76:120-126.

40. Teglas MB, Foley J: Differences in the transmissibility of two Anaplasma phagocytophilum strains by the North American tick vector species, Ixodes pacificus and Ixodes scapularis (Acari: Ixodidae). Exp Appl Acarol 2006, 38:47-58.

41. Courtney JW, Kostelnik LM, Nordin SZ, Massung RF: Multiplex Real-Time PCR for detection of Anaplasma phagocytophilum and Borrelia burgdorferi. J Clin Microbiol 2004, 42:3164-3168.

42. Massung RF, Slater K, Owens JH, Nicholson WL, Mather TN, Solberg VB, Olson JG: Nested PCR assay for detection of granulocytic ehrlichiae. J Clin Microbiol 1998, 36:1090-1095.

43. Lin Q, Rikihisa Y, Massung RF, Woldehiwet Z, Falco RC: Polymorphism and Transcription at the p44-1/p44-18 Genomic Locus in Anaplasma phagocytophilum Strains from Diverse Geographic Regions. Infect Immun 2004, 72:5574-5581.

44. Bown KJ, Lambin X, Ogden NH, Petrovec M, Shaw SE, Woldehiwet Z, Birtles RJ: High-resolution genetic fingerprinting of European strains of Anaplasma phagocytophilum by use of multilocus variable-number tandem-repeat analysis. J Clin Microbiol 2007, 45:1771-1776.

45. Chenna R, Sugawara H, Koike T, Lopez R, Gibson TJ, Higgins DG, Thompson JD: Multiple sequence alignment with the Clustal series of programs. Nucleic Acids Res 2003, 31:3497-500.

46. Felsenstein J: PHYLIP - phylogeny interference package (version 3.2). Cladistics 1989, 5:164-166.

doi:10.1186/1756-3305-4-161

Cite this article as: Silaghi et al:: Genetic variants of Anaplasma phagocytophilum from 14 equine granulocytic anaplasmosis cases. Parasites \& Vectors 2011 4:161.

\section{Submit your next manuscript to BioMed Central and take full advantage of:}

- Convenient online submission

- Thorough peer review

- No space constraints or color figure charges

- Immediate publication on acceptance

- Inclusion in PubMed, CAS, Scopus and Google Scholar

- Research which is freely available for redistribution

Submit your manuscript at www.biomedcentral.com/submit 